\title{
Avaliação comparativa do desempenho de três cadeias de suprimentos em manufatura
}

\author{
Miguel Afonso Sellitto \\ Lia Weber Mendes \\ Unisinos
}

\begin{abstract}
Resumo
Este trabalho apresenta um caso de avaliação do desempenho de três cadeias de suprimentos em manufatura. Este tipo de avaliação pode realimentar ações de controle que visem a atingir objetivos estratégicos da cadeia e pode ser útil em benchmarking. A metodologia proposta parte do modelo SCOR de gestão de cadeias de suprimento. As idéias do modelo foram estruturadas e associadas a dimensões de desempenho, cujas importâncias relativas foram calculadas por especialistas, com o auxílio do AHP. As dimensões foram estruturadas em vinte e cinco indicadores categóricos, avaliados pelos pesquisadores e por gestores das cadeias. A metodologia foi aplicada em três cadeias de suprimentos com similaridades. Os resultados foram analisados e entende-se que possam servir como passo intermediário em direção a uma eventual futura teoria sobre medição de desempenho em cadeias de suprimentos.
\end{abstract}

Palavras-chave

Avaliação de desempenho em cadeia de suprimentos, modelo SCOR, benchmarking em cadeias de suprimentos, medições em cadeias de suprimentos.

\section{Comparative performance assessment in three supply-chains in manufacturing}

\begin{abstract}
This paper presents a case in which the performance of three supply-chains in manufacturing had been assessed. Performance assessment can feedback strategic control in supply-chain management and can be useful in benchmarking processes. The employed methodology is derived from the SCOR model supply-chain management reference model. Ideas from the model were structured and associated to performance dimensions in supply-chains, prioritized by experts with the aid of AHP. Dimensions were structured in twenty-five categorical indicators, assessed by researchers and managers of the supply-chains. The methodology was applied in three supply-chains, with similarities. Results were analyzed and we think that can perform an intermediate step toward a future theory regarding performance measurements in supply-chains.
\end{abstract}

Key words

Supply-chain performance assessment, SCOR model, supply-chain benchmarking, supply-chain performance measures. 


\section{INTRODUĈ̣̃O}

Um tipo de arranjo interorganizacional que tem sido adotado em operações de manufatura é a cadeia de suprimentos (supply-chain, SC). SCs são perpassadas por fluxos de materiais e informações, desde os fornecedores do fornecedor até os clientes do cliente da empresa focal. Em SCs, cada participante usa competências individuais segundo uma estratégia compartilhada de atendimento a clientes, pois são estes que aportam recursos financeiros ao arranjo: nas operações internas, o dinheiro apenas troca de mãos entre participantes.

Para Cooper e Ellram (1993), a integração de operações na SC está entre a integração vertical completa e a autonomia individual plena: partes individuais têm autonomia para perseguir objetivos globais. Para Christopher (2002), a SC é uma rede de organizações, com ligações nos dois sentidos, de processos e atividades que produzem bens e serviços requeridos por clientes finais. Para Simch-Levi, Kaminski e Simch-Levi (2003), a SC envolve mais do que processos logísticos de armazenagem e transporte: envolve todos os processos de negócio requeridos para atender clientes finais. Para Ribeiro (2003), devido à diversidade observada nos processos logísticos, há dificuldade em comparar desempenhos entre SCs. Para Lambert e Pohlen (2001), futuras pesquisas deveriam endereçar a proposição e o teste de métodos de medição de desempenho em SC. Os autores atribuem esta carência, entre outras causas, à complexidade que surge quando múltiplos indivíduos formam um arranjo com objetivos compartilhados.

Uma referência em gestão em SC é o modelo SCOR (Supply-Chain Operations Reference), desenvolvido pelo SCC (Supply-Chain Council), integrado por praticantes de manufatura, serviços, distribuidores e varejistas. O modelo incentiva melhorias contínuas pela proposição de processos, métricas e fundamentação teórica (SCC, 2003).

Tomando como base teórica o SCOR, e usando o método multicritério AHP, o PPGEPS-UNISINOS desenvolveu um método que pode ser útil na avaliação de desempenho em SC. O objetivo deste artigo é apresentar um estudo de caso em que o método foi usado para avaliar e comparar o desempenho de três SCs manufatureiras. O estudo visou a testar e robustecer a idéia central do método: usar o SCOR para gerar dimensões de desempenho, ponderadas pelo AHP, e desdobradas em indicadores que, medidos fisicamente ou avaliados categoricamente, sintetizem um índice global de desempenho da SC. O método de pesquisa é o estudo de caso exploratório, pois esta é a aplicação inicial da idéia.

Algumas incidências na literatura têm algo a ver com a pesquisa e foram consultadas. Beamon (1999) apresen- ta e classifica indicadores usados em SC manufatureira. Lambert e Pohlen (2001), Gunasekaran, Patel e Tirtiroglu (2001) e Gunasekaran, Patel e McGaughey (2004) desenvolvem quadros de trabalho para medir desempenho em SC. Hoek (1998) usa indicadores para controle de desempenho em SC. Lai, Ngai e Cheng (2002) constroem um sistema com vinte e seis indicadores de desempenho em SC de transportes. Kleijnen e Smits (2003) usam o BSC para estruturar a medição de desempenho em SC. Gilmore (1999) apresenta um quadro de trabalho para benchmarking em SC. Holmberg (2000) sugere uma perspectiva sistêmica que previna a fragmentação de medições em SCs. Chan e Qi (2003) usam um método baseado nos processos da SC para criar um sistema de medição de desempenho. Chan (2003) usa o AHP para priorizar dimensões de desempenho em SC, extraídas de referenciais em estratégia de operações: custo; eficiência; qualidade; flexibilidade; velocidade na inovação; confiabilidade e intensidade de inovação. A presente pesquisa tem similaridade com Chan (2003) quanto ao uso do AHP, porém em dimensões extraídas do SCOR: planejamento geral; fornecimento; fabricação; distribuição e retorno.

\section{Devido à diversidade observada nos processos logísticos, há dificuldade em parar desempenhos entre SCs.}

O restante do artigo está organizado em: (i) revisão teórica; (ii) metodologia e aplicação; (iii) discussão e contribuição do caso; e (iv) conclusões e continuidade.

\section{O MODELO SCOR DE REFERÊNCIA DE GESTÃO EM SC}

Um modelo de referência integra conceitos em um instrumento unificado, formando uma estrutura sistêmica de referência em um campo de gestão. Exemplos de modelos de referência são o Prêmio Nacional da Qualidade, o PNQ, no Brasil, e os prêmios Malcolm Baldridge, nos Estados Unidos, Deming, no Japão, e Shingo, na NAFTA. Descrições surgem em FPNQ (2006), BNQP (2006), W. Edward Deming Institute (2006) e Shingo Prize (2006).

Um modelo de referência inclui ao menos: (i) um método para a proposição de objetivos; (ii) uma teoria capaz de sugerir ações para atingir os objetivos; e (iii) uma técnica de medição de desempenho que realimente os resultados das ações. Tais conceitos, integrados em um modelo de gestão, surgem na Figura 1.

O modelo de interesse para este artigo é o SCOR. Este 
é um modelo de referência de gestão, pois inclui técnicas de benchmarking, reengenharia e medição de desempenho por indicadores, temas encontrados em Davenport (1994), Born (1994) e Camp (1994). O SCOR cria uma linguagem comum, propõe uma abordagem para alinhar objetivos e cria um foro para discussões entre membros de SCs. Foi concebido como ferramenta de diagnose padronizada para focar, comunicar e compartilhar perspectivas, estratégias, melhores práticas e tecnologias de gestão de SC. O SCOR descreve atividades em SC, endereçando cinco macroprocessos (Quadro 1 e Figura 2): planejamento, que antecipa os demais, fornecimento, produção, entrega e retorno. Os macroprocessos se dividem em subprocessos, para os quais são definidos atributos de desempenho e instruções de melhores práticas, permitindo a comparação e a transferência de conhecimento entre SCs (SCC, 2003).

O SCOR usa três níveis de análise. O primeiro nível define escopo de operações, objetivos de desempenho competitivo e métricas primárias, conforme cinco atributos de desempenho: confiabilidade, velocidade, flexibilidade, custo e eficiência em ativos. O segundo nível configura as operações, define a estratégia da empresa focal e descreve os subprocessos dentro dos macroprocessos, segundo três classes: planejamento, execução e suporte. Finalmente, no terceiro nível, são definidos os elementos e informações de entrada e saída de cada processo, as métricas de desempenho, as melhores práticas na classe e requisitos específicos de participantes. Com ferramentas de mapeamento de processos, detalham-se os fluxos de informações e materiais, entradas, saídas, fornecedores, destinatários e lógicas de operação, estimulando a comparação com as melhores práticas conhecidas e melhorias em atividades operacionais da SC (SCC, 2003).

Em resumo, o nível um divide a $\mathrm{SC}$ em macroprocessos, estabelece metas globais e acompanha macroindicadores; o nível dois formula estratégias de planejamento, execução e suporte aos macroprocessos; o nível três detalha as atividades que executarão as estratégias do nível dois e buscarão os objetivos do nível um (SCC, 2003).

Figura 1: Conceitos integrados em modelo de gestão.

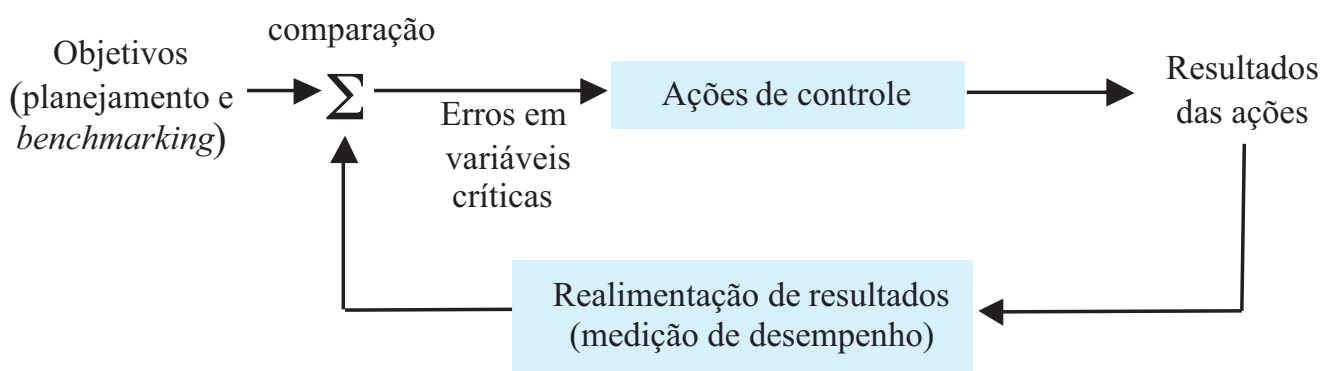

Quadro 1: Macroprocessos do SCOR.

\begin{tabular}{|l|l|}
\hline MACRO-PROCESSOS & \multicolumn{1}{c|}{ ATIVIDADES } \\
\hline Planejamento & Desenvolve diretrizes, formula objetivos e planeja os outros macroprocessos. \\
\hline Fornecimento & $\begin{array}{l}\text { Identifica fornecedores, negocia contratos e parcerias de longo prazo, programa entregas, } \\
\text { recebimentos, inspeções, transferências e pagamentos. }\end{array}$ \\
\hline Fabricação & $\begin{array}{l}\text { Manufatura os itens, segundo estratégias de produção para estoque, sob encomenda ou sob } \\
\text { projeto, monta, inspeciona e embala os itens. }\end{array}$ \\
\hline Entrega & $\begin{array}{l}\text { Processa pedidos, define datas de entrega, consolida cargas, estabelece rotas, contrata } \\
\text { veículos, assegura a carga, carrega, transporta e paga o transportador. }\end{array}$ \\
\hline Retorno & $\begin{array}{l}\text { Devolve matérias-primas ou produtos excessivos, indevidas ou devolvidos por clientes, } \\
\text { analisa falhas, ressarce eventuais prejuízos. }\end{array}$ \\
\hline
\end{tabular}

Fonte: Ribeiro, 2003. 


\section{MEDIC̣ÃO DE DESEMPENHO E BENCHMARKING EM SC}

O interesse pela medição de desempenho empresarial aumentou a partir dos anos 1990, principalmente pela insatisfação com metodologias baseadas principalmente em resultados financeiros passados. Resenhas parciais de metodologias já propostas surgem em Bititci et al. (2002), Gomes, Yasim e Lisboa (2004) e Melnick, Stewart e Swink (2004).

Pires (2004) define desempenho como a informação quantificada do resultado de processos, que pode ser comparada com metas, padrões, resultados passados e outros processos. Para Hronec (1993), as medições de desempenho são sinais vitais da organização, comunicando a estratégia para baixo e os resultados para cima, e englobando a totalidade do entendimento de metas, métodos e relações causa-efeito consideradas na estratégia. Para Melnick, Stewart e Swink (2004), a medição de desempenho conecta estratégia e realidade: estratégia sem medição é inútil, medição sem estratégia não faz sentido. Para Pires (2004), antes de formular as medições, deve-se identificar a estratégia, o que pode ser difícil em SC, pois uma empresa pode participar de várias cadeias, com estratégias diferentes.

Para Pires (2004), a competição passou a ocorrer entre cadeias e não mais apenas entre empresas individuais: mesmo que o embate seja visível junto ao cliente, a competitividade é construída por uma estratégia que engloba toda a cadeia. Segundo Lambert e Pohlen (2001), um sistema comum de medição de desempenho pode aumentar a chance de sucesso no atendimento de objetivos de clientes, tais como redução de preços e de prazos de entrega, e de objetivos da SC, tais como redução de custos ou de estoques intermediários. Tais opiniões sugerem que se devam manter sistemas individuais de medição de desempenho, mas acrescentar indicadores comuns que reflitam a ação de cadeia. São os indicadores comuns que alinharão os esforços da cadeia como um todo aos esforços locais, encorajando a perseguição dos objetivos individuais e, principalmente, dos objetivos de cadeia.

Segundo Simch-Levi, Kaminski e Simch-Levi (2003), sendo uma rede complexa de instalações e organizações, a

Figura 2: Estrutura do SCOR.

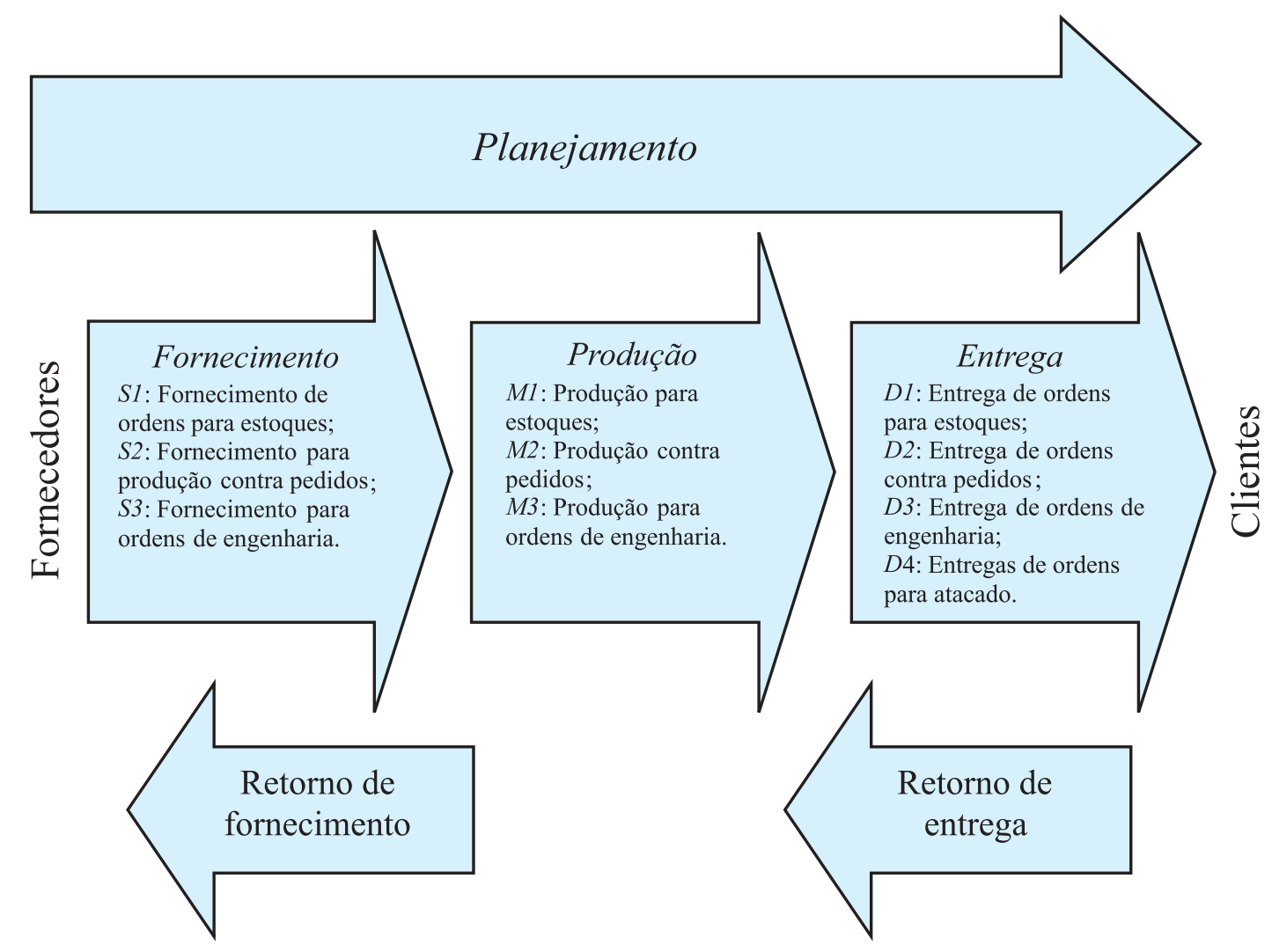

Fonte: SCC, 2003 
SC pode abrigar objetivos e estratégias parciais conflitantes. Sempre que partes individuais são agrupadas, podem surgir emergências e imprevisibilidades que dificultam a formulação de objetivos comuns e de estratégia compartilhada. Como a base conceitual da medição de desempenho foi construída para unidades individuais, abre-se uma pauta de pesquisa: lançar novas bases conceituais ou modificar as existentes para a medição de desempenho em arranjos complexos como SCs.

Para medir a complexidade em SC, Hansen (2004) propõe uma abordagem meso-analítica. Gasparetto (2003) propõe análise em arborescência. Pires e Aravechia (2001) propõem uma abordagem gráfica em forma de radar, na qual indicadores evoluem ao longo da cadeia. Beamon (1999) prescreve abrangência, universalidade, mensurabilidade, consistência e conectividade. A abrangência mede todas as pertinências da cadeia; a universalidade permite comparação; a mensurabilidade exige fácil obtenção dos dados; a consistência exige que a avaliação reflita a estratégia da cadeia; e a conectividade possibilita que sistemas parciais de avaliação se conectem em um sistema integrado. Dornier et al. (2000) alertam que a medição do desempenho de SC deve monitorar, além dos processos logísticos de execução, a modificação de objetivos e a validade dos pressupostos assumidos na formulação da estratégia. Em suma, os indicadores devem acompanhar a execução e as modificações na estratégia e no cenário de competição da SC.

A avaliação também serve para ordenar SCs para benchmarking. O benchmarking avalia uma operação e a compara com práticas similares em outras empresas, estimulando melhorias, inovações e formalizando o gerenciamento da mudança, ajudando a identificar os motivos das diferenças nos resultados (PULAT, 1994). Para Bowersox e Closs (2001), o benchmarking é essencial na avaliação de desempenho de $\mathrm{SC}$, pois identifica medidas de desempenho, processos, estrutura organizacional, sistemas de informação, instalações, equipamentos e relações dentro da SC. O benchmarking pode se valer de julgamentos categóricos, o que remete a discussão às grandezas intangíveis.

\section{MENSURAC̣ÃO E ESTRUTURAC̣ÃO DE GRANDEZAS INTANGIVEIS}

A mensuração de grandezas intangíveis é recorrente em pesquisa e é abordada pela teoria da mensuração (measurement theory), um campo de conhecimentos situado entre a matemática e a filosofia da ciência. A teoria trata de modelos numéricos que estruturam descrições qualitativas de crenças ou preferências de indivíduos, geralmente no papel de decisores. Da matemática, a teoria requisita a análise e a modelagem estatística multivariada; da filosofia da ciência, requisita a noção de causalidade em objetos (FRENCH, 1986).

A teoria da mensuração descreve grandezas ou características intangíveis em objetos, segundo formatos relacionais.

Por ora, interessa o formato racional, que admite relações de preferência ou de indiferença, e rejeita indecisões e incomparabilidades. Por exemplo, sejam $A$ e $B$ duas características presentes em um objeto e que, para um dado fim, mantenham entre si relações, tais como: (i) $A$ é preferível a $B, A$ é indife-

Pires (2004) cita um trabalho de 1994 em que praticantes, acadêmicos e consultores desenvolveram medidas de desempenho em SC, abrangendo quatro construtos: satisfação do cliente, tempo, custo e uso de recursos. Outra abordagem é possível, baseada em Voss (1995). Segundo este autor, estratégias em produção têm adotado três linhas de ação: (i) fixar as capacidades internas segundo requisitos externos de competição; (ii) fazer escolhas que compatibilizam aspectos externos, de mercado, e internos, de recursos produtivos; e (iii) adotar as chamadas melhores práticas, tais como a produção enxuta ou a qualidade total, se possível sintetizadas em modelos de referência de gestão. Entende-se que seja possível propor um sistema de avaliação de desempenho de SC baseado na terceira linha, com o uso do modelo SCOR. Por ora fala-se em avaliação ou julgamento de desempenho, deixando o termo medição para quando for possível usaremse variáveis de medição física. rente a $B$ ou $B$ é preferível a $A$; e (ii) dado que $A$ é preferível a $B$, esta preferência é pequena, média ou grande. French (1986) demonstra que é possível representar por números coerentes um conjunto de relações qualitativas que expresse uma estrutura de preferências de um decisor racional sobre as características de um objeto.

Mensurações se valem de variáveis. Uma variável é um conjunto de medidas associadas a um fator discernível em um objeto e podem ser quantitativas, se associáveis a números, ou qualitativas, se associáveis a categorias. A escala de Likert pode representar numericamente o estado de uma variável qualitativa [ótimo $=5$, bom $=4$, regular $=3$, ruim $=2$, péssimo $=1$ ], apreendendo as idéias de oposição e relatividade entre categorias, presentes em julgamentos de decisores racionais (PEREIRA, 1999).

Para estudar grandezas intangíveis, deve-se lançar mão de construções abstratas que facultem a investigação por 
componentes estruturais. A construção mais abstrata é o termo teórico, que compreende e se sustenta em construtos, que, por sua vez, se sustentam em conceitos. Construtos e conceitos também são abstratos, porém o conceito é mais próximo da realidade e já é representável por variáveis manifestas, os indicadores. O construto é representável por variáveis latentes, não mensuráveis diretamente, mas calculadas a partir dos indicadores (LAKATOS e MARCONI, 1991; HAIR et al., 1998).

Construtos e conceitos estruturam uma grandeza intangível em níveis hierárquicos, nos quais um ente superior é influenciado por entes inferiores, que, por sua vez, são influenciados por entes sucessivamente inferiores. Entes de mesma hierarquia influenciam o grupo acima e são influenciados pelos grupos abaixo. A hierarquia é construída por uma teoria, por conhecimento empírico ou por opinião de decisores sobre a situação de interesse, organizados por instrumentos de representação de relações, tais como mapas cognitivos ou árvores de realidade. Hierarquias podem ser representadas por estruturas arborescentes, nas quais um critério é afetado por critérios subordinados, mutuamente exclusivos e que descrevem exaustivamente o critério superior. Para cada critério superior, deve haver, ao menos, dois critérios inferiores, como na Figura 3 (ENSSLIN, MONTIBELLER e NORONHA, 2001).

Em medição de desempenho, nem sempre é possível estruturar o objetivo em hierarquia de objetivos independentes: pode haver interferências mútuas e não-linearidades. Tais situações podem envolver nebulosidades e sombreamentos, o que torna a percepção mais complexa e sujeita a variabilidades. Para Saaty (1991), nestes casos, a percepção humana da realidade ocorre em três estágios: (i) decompo-

Figura 3: Estrutura arborescente.

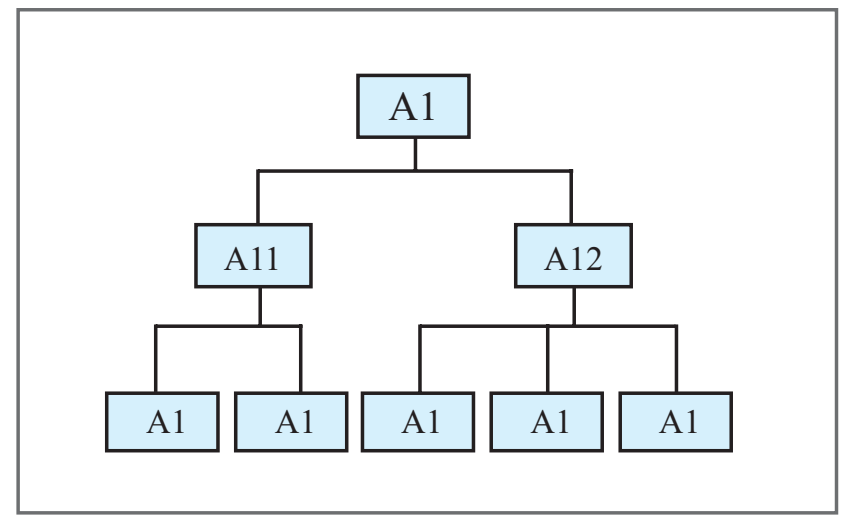

sição da complexa realidade em partes; (ii) descoberta das relações de influência entre as partes; e (iii) síntese ponderada do todo, em um veículo hierárquico simplificado da realidade complexa, mas que contém o peso final, resultante das mútuas influências. A representação usa elementos mutuamente independentes e hierarquias lineares, sem circularidades. Uma discussão sobre representações não-lineares e interdependência é encontrada em Salomon e Montevechi (1998) e seu estudo é remetido à continuidade de pesquisa. grupo focado de cinco pesquisadores criou
uma estrutura apriorística, que representa a grandeza intangível Desempenho da Cadeia de Suprimentos, um termo teórico, suportado pelos cinco macroprocessos do SCOR, os construtos.

\section{Hierarquias, decisão multicriterial e uso do AHP}

Hierarquias lineares são veículos de análise que podem ser úteis em decisão multicriterial. Tais hierarquias oferecem uma estrutura de preferências de decisores, que pode ser expressa por uma matriz de preferência, na qual $a_{i j}$ é o valor atribuído por um decisor à alternativa $i$, julgada por seu desempenho ao influenciar o critério $j$. A estrutura de preferências surge por comparação pareada de alternativas, sob quatro relações: indiferença, preferência estrita, preferência fraca e incomparabilidade.

Sejam $a$ e $b$ duas alternativas de decisão para um problema. Na indiferença, $a$ e $b$ se equivalem ( $a$ I $b$ ou $a \sim b)$ e o decisor estará satisfeito, tanto com $a$ como com $b$. Na preferência estrita, há a preferência de $a$ em relação a $b(a \mathrm{P} b$ ou $a$ $\succ b)$. Na preferência fraca, as razões existentes não implicam $(a \mathrm{P} b)$ mas também não são suficientes para implicar ( $a$ I $b$ ): $a$ é ao menos tão bom quanto $b$. Na incomparabilidade $(a \mathrm{R} b)$, ou não há informações suficientes para a preferência ou as alternativas enfocam objetivos diferentes (GOMES, GOMES e ALMEIDA, 2002).

Para esta pesquisa interessam decisões racionais, que não admitem incomparabilidade nem preferência fraca e preferências que cumpram as seguintes condições: (i) ( $a \sim$ $a)$; (ii) se $(a \succ b)$ e $(b \succ c)$, então $(a \succ c)$; e (iii) se $(a \sim b)$ e $(b \sim c)$, então $(a \sim c)$.

O método AHP (Analytic Hierarchy Process) pode ser usado na quantificação de preferências de decisores. Segundo Saaty (1991), o método agrupa partes de uma situação complexa, segundo propriedades comuns, identifica os fatores influentes e mede o peso de sua influência, comparando-os aos pares e traduzindo as importâncias re- 
lativas em uma escala. Preenchida a matriz de comparação, calcula-se o autovetor de máximo autovalor, que prioriza os fatores, informando as importâncias relativas. O autovalor mede a razão de consistência $C R$, que ajuda a manter baixa a inconsistência do julgamento e, por conseqüência, os sombreamentos da hierarquia. Saaty (1991) sugere aceitar $C R<0,10$. Em caso contrário, sugere revisar os julgamentos ou até mesmo a própria hierarquia.

O método opera em três passos: (i) descrição do objeto como hierarquia; (ii) comparação pareada entre partes da hierarquia; e (iii) computação dos resultados. Divide-se o objeto em níveis hierárquicos e fazem-se $n .(n-1) / 2$ comparações pareadas. Cada nível ou critério $a_{i}$ é comparado com os demais critérios $a_{j}$ de mesma hierarquia, gerando a matriz de preferências $C_{i, j}(n \times n)$, construída conforme os valores da tabela 1 (SAATY, 1991).

\section{A PESQUISA}

O método de pesquisa é o estudo de caso. Este método examina em profundidade um fenômeno contemporâneo, em seu contexto, especialmente quando os limites entre fenômeno e contexto não são definidos. $\mathrm{O}$ estudo de caso pode ser exploratório, levantando hipóteses e propondo questões de pesquisa para futuros estudos; descritivo, buscando associações entre variáveis qualitativas ou quantitativas; ou explanatório, descrevendo os fatos de interesse e propondo explicações aceitáveis e verificáveis para estes fatos (YIN, 2001). Segundo Eckstein et al. (1975, apud ROESCH, 1999), um estudo de caso pode contribuir para uma teoria de cinco modos: (i) oferecer, para posteriores estudos, uma descrição profunda e específica do objeto; (ii) interpretar eventuais regularidades no objeto como evidência de postulados teóricos mais gerais; (iii) testar uma idéia sobre o objeto em uma situação deliberadamente construída; (iv) sondar plausivelmente uma teoria já proposta sobre o objeto; e (v) apoiar ou refutar uma teoria já sondada.

O presente caso é do tipo exploratório: ao fim, resultou uma hipótese de trabalho. A contribuição é do terceiro tipo: foi testada uma idéia, que poderá ser reforçada ou refutada por outros estudos. A questão de pesquisa foi: como avaliar numericamente e classificar o desempenho de cadeias de suprimentos?

O grupo de pesquisa foi composto por três praticantes em logística, graduados em engenharia de produção, um doutor líder de pesquisa e um mestre, ambos com atuação acadêmica e experiência prática em consultoria e operação logística. A metodologia de trabalho foi: (i) trabalho de análise: reunião dos cinco membros do grupo de pesquisa em diversas sessões de grupo focado, mediados pelo líder, na qual foi construída uma estrutura de desempenho em SC, que, após, com a participação de gestores de SC, foi ponderada com o apoio do AHP; (ii) trabalho de campo: em diversas visitas de campo, entrevistas em profundidade com diversos gestores de $\mathrm{SC}$ e análise de documentos das empresas, foi avaliado o desempenho de três SC, segundo a estrutura construída; e (iii) contribuição para continuidade de pesquisa: uso extrapolado da estrutura, para sugerir indicadores objetivos, de medição física na SC.

São delimitações, que poderão ser relaxadas em outras aplicações do método: (i) avaliação categórica, não medição física; (ii) SC manufatureiras; e (iii) uso do AHP.

\section{Estrutura de desempenho em SC}

$\mathrm{O}$ grupo focado criou uma estrutura apriorística, que representa a grandeza intangível Desempenho da Cadeia de Suprimentos, um termo teórico, suportado pelos cinco macroprocessos do SCOR, os construtos. Cada construto é suportado por cinco conceitos.

O construto Planejamento corresponde à definição da estratégia da cadeia e é sustentado pelos conceitos de: alinhamento estratégico, formulação das estratégias, desdobramento das estratégias, medição das estratégias e gestão e política da qualidade. O construto Fornecimento corresponde às operações de fornecedores e se sustenta em: flexibilidade, pontualidade, qualidade intrínseca de bens e serviços, condições de negociação e custos no fornecimento. A fabricação se sustenta em: flexibilidade, velocidade, qualidade, confiabilidade de processos e custos na manufatura. A entrega se sustenta em: flexibilidade, pontualidade, qualidade, condi-

Tabela 1: Preferências em comparação pareada.

\begin{tabular}{|l|c|l|l|}
\hline \multicolumn{1}{|c|}{$\mathbf{a}_{i}$ em relação $\mathbf{a} \mathbf{a}_{i}$} & $\mathbf{c}_{i j}$ & \multicolumn{1}{c|}{$\mathbf{a}_{i}$ em relação $\mathbf{a} \mathbf{a}_{i}$} & $\mathbf{c}_{i j}$ \\
\hline igual & 1 & igual & 1 \\
\hline mais importante & 3 & menos importante & $1 / 3$ \\
\hline muito mais importante & 5 & muito menos importante & $1 / 5$ \\
\hline extremamente mais importante & 7 & extremamente menos importante & $1 / 7$ \\
\hline absolutamente dominante & 9 & absolutamente irrelevante & $1 / 9$ \\
\hline
\end{tabular}

Fonte: Saaty, 1991. 
Quadro 2: Estrutura de desempenho em SC.

\begin{tabular}{|c|c|c|}
\hline CONSTRUTO & CONGEITO & DESCRIÇÃO DO GONCEITO \\
\hline \multirow{5}{*}{ planejamento } & $\begin{array}{l}\text { alinhamento } \\
\text { estratégico }\end{array}$ & $\begin{array}{l}\text { como é a inter-relação dos participantes na SC e suas aderências à estratégia } \\
\text { geral da cadeia }\end{array}$ \\
\hline & $\begin{array}{l}\text { formulação das } \\
\text { estratégias }\end{array}$ & como é formulada a estratégia de SC \\
\hline & $\begin{array}{l}\text { desdobramento } \\
\text { da estratégia }\end{array}$ & $\begin{array}{l}\text { como a cadeia desdobra a estratégia em ações individuais, estabelece metas e } \\
\text { acompanha a execução estratégica }\end{array}$ \\
\hline & $\begin{array}{l}\text { medição do } \\
\text { desempenho }\end{array}$ & $\begin{array}{l}\text { como a cadeia define e implementa a medição do desempenho e de que forma os } \\
\text { participantes realimentam a estratégia }\end{array}$ \\
\hline & $\begin{array}{l}\text { gestão da } \\
\text { qualidade }\end{array}$ & $\begin{array}{l}\text { como a cadeia opera sistemas de qualidade e estimula melhoria contínua nos } \\
\text { participantes e na cadeia }\end{array}$ \\
\hline \multirow{5}{*}{ fornecimento } & flexibilidade & $\begin{array}{l}\text { como é o nível de flexibilidade quanto a modificações nas quantidades e nas } \\
\text { variedades e em fornecimentos emergenciais }\end{array}$ \\
\hline & pontualidade & $\begin{array}{l}\text { como é a confiabilidade em relação ao cumprimento das entregas nas datas } \\
\text { devidas e ao nível de serviço }\end{array}$ \\
\hline & qualidade & $\begin{array}{l}\text { como é o fornecimento de produtos quanto a avarias, conformidade a } \\
\text { especificações técnicas e integralidade dos lotes (quantidades) }\end{array}$ \\
\hline & $\begin{array}{l}\text { condições de } \\
\text { negociação }\end{array}$ & $\begin{array}{l}\text { como se distribui a governança e o nivelamento em relação ao poder de negociação } \\
\text { de prazos, tamanhos de lote e periodicidades }\end{array}$ \\
\hline & custos & $\begin{array}{l}\text { como são, no fornecimento, os custos de fornecimento relativamente a } \\
\text { concorrentes e requisitos de mercado }\end{array}$ \\
\hline \multirow{5}{*}{ fabricação } & flexibilidade & $\begin{array}{l}\text { como é, na fabricação, o nível de flexibilidade quanto a modificações nas } \\
\text { quantidades, variedades e em fornecimentos emergenciais }\end{array}$ \\
\hline & velocidade & como é, na fabricação, a confiabilidade de cumprimento de datas devidas \\
\hline & qualidade & $\begin{array}{l}\text { como é, na fabricação, a conformidade a requisitos técnicos e a capabilidade dos } \\
\text { produtos para requisitos de variabilidade }\end{array}$ \\
\hline & processo & $\begin{array}{l}\text { como é a confiabilidade, a consistência e a capabilidade dos processos de } \\
\text { fabricação, }\end{array}$ \\
\hline & custo & $\begin{array}{l}\text { como e de que tipo são os esforços desenvolvidos para redução de custos de } \\
\text { produção }\end{array}$ \\
\hline \multirow{5}{*}{ entrega } & flexibilidade & $\begin{array}{l}\text { como é a flexibilidade em relação a modificações em quantidades e variedades, e } \\
\text { em fornecimentos emergenciais }\end{array}$ \\
\hline & pontualidade & como é a confiabilidade das entregas nas datas devidas \\
\hline & qualidade & $\begin{array}{l}\text { como é a entrega de produtos quanto a avarias, conformidade a especificações } \\
\text { técnicas e integralidade da carga }\end{array}$ \\
\hline & $\begin{array}{l}\text { condições de } \\
\text { negociação }\end{array}$ & $\begin{array}{l}\text { como se distribui a governança e o nivelamento em relação ao poder de negociação } \\
\text { de prazos, tamanhos de lote e periodicidade }\end{array}$ \\
\hline & custos & $\begin{array}{l}\text { como são os custos de fornecimento com relação a concorrentes e requisitos de } \\
\text { mercado na entrega }\end{array}$ \\
\hline
\end{tabular}


continuação

\begin{tabular}{|l|l|l|}
\hline CONSTRUTO & \multicolumn{1}{|c|}{ CONGEITO } & \multicolumn{1}{c|}{ DESCRIÇÃ̃o DO CONCEITO } \\
\hline \multirow{5}{*}{ retorno } & reciclabilidade & $\begin{array}{l}\text { como é a importância dada pela cadeia a embalagens retornáveis e } \\
\text { reaproveitamento de resíduos }\end{array}$ \\
\cline { 2 - 3 } & $\begin{array}{l}\text { devolução de } \\
\text { itens }\end{array}$ & $\begin{array}{l}\text { como é a metodologia para recebimento de devoluções de vendas, de embalagens } \\
\text { retornáveis e de descartes de produtos usados }\end{array}$ \\
\cline { 2 - 3 } & $\begin{array}{l}\text { conformidade } \\
\text { legal }\end{array}$ & $\begin{array}{l}\text { de que modo são atendidas as normas e os preceitos legais exigidos das } \\
\text { operações da SC }\end{array}$ \\
\cline { 2 - 4 } & $\begin{array}{l}\text { custos de } \\
\text { devolução }\end{array}$ & $\begin{array}{l}\text { como são os custos de retorno, comparando ao mercado e segundo a realidade do } \\
\text { processo }\end{array}$ \\
\cline { 2 - 3 } & ética ambiental & $\begin{array}{l}\text { como é o posicionamento da cadeia quanto à questão ambiental, certificações e } \\
\text { demais legislações pertinentes }\end{array}$ \\
\hline
\end{tabular}

ções de negociação e custos na entrega. O retorno se sustenta em: reciclabilidade dos materiais, devolução de itens, conformidade legal, custos de devolução e ética ambiental. O Quadro 2 apresenta a estrutura.

\section{Ponderação da estrutura e avaliação de três SC}

O grupo de cinco pesquisadores identificou três SCs com similaridades mútuas e convidou os três gestores de cadeia a participar dos trabalhos de campo. Estes gestores são funcionários das empresas focais e têm autonomia para coordenar os esforços de SC para o atingimento dos objetivos de desempenho de toda a cadeia.

\section{grupo de cinco pesquisadores identificou três SCs com similaridades mútuas e convidou os três gestores de cadeia a participar dos trabalhos de campo.}

indústrias químicas, automobilísticas, transporte multimodal ou produtos de consumo pessoal, são remetidas à continuidade de pesquisa.

Os produtos principais das três SCs são: materiais de segurança; motores elétricos; e moldes e matrizes para peças injetadas. Para exemplificar o contexto, descreve-se a primeira SC.

A cadeia tem operações de fornecimento a três unidades de manufatura, quatro operações de transporte e três centros de distribuição. O fornecimento ocorre em duas linhas dominantes, petroquímicos e metálicos, fornecidos localmente às manufaturas $\mathrm{P}$ e M, que produzem peças técnicas plásticas e metálicas. As manufaturas $\mathrm{P}$ e M fornecem por modal rodoviário à manufatura $\mathrm{N}$, que agrega peças técnicas importadas por via marítima e embalagens locais, montando o produto final. A manufatura $\mathrm{N}$ remete por modal rodoviário a três $\mathrm{CDs}$, nas regiões sul, sudeste e nordeste do Brasil. A entrega ao varejo também é feita por modal rodoviário. Os varejistas encomendam aos CDs, que fazem as entregas e geram faltas nos estoques.

As similaridades estão nos processos produtivos (fornecimentos mais importantes concentrados em peças metálicas, plásticas e embalagens; fabricação com base tecnológica e segundo sistemas de gestão da produção; montagem de subconjuntos concentrada na empresa focal; distribuição por modal rodoviário, baseada em centros de distribuição, entregas locais e clientes empresariais); na governança, localizada sempre na empresa focal, que tem autonomia para gerar restrições e formular estratégias para a SC; existência de um órgão gestor da SC; e estratégia de desenvolvimento de produto: as três SCs suportam seus produtos por engenharia simultânea e tecnologia de informação. Outros tipos de SC, tais como as envolvendo
Atingidos os níveis de reposição, os CDs encomendam à manufatura $\mathrm{N}$, que repassa às manufaturas $\mathrm{P}$ e $\mathrm{M}$, importações e embalagens. O fluxo de retorno de embalagens nasce no varejo e chega à manufatura $\mathrm{N}$, aproveitando as rotas rodoviárias do fluxo direto.

A Figura 4 mostra um grafo da SC. As linhas pontilhadas separam as fases: fornecimento, fabricação e entrega.

Antes dos trabalhos de campo, os três gestores e os três praticantes aplicaram o AHP aos construtos, sob supervisão metodológica do líder de pesquisa, que operou como analista de decisão. Este solicitou que os seis decisores considerassem, nos julgamentos, a situação atual das SCs estudadas, em conjunto com crenças, experiências e conhecimentos de 
gestão. Houve dez julgamentos de importância relativa por comparação pareada, resultando uma $C R=0,09$, considerada satisfatória pelo analista. A matriz de julgamentos surge no Quadro 3 e produziu importâncias relativas (autovetor de maior autovalor, equação 1), que refletem a média da situação atual das cadeias. Por exemplo, uma importância de $5,5 \%$ para o fornecimento reflete que este item, no momento, está mais bem resolvido nas três SC's do que a fabricação, cuja importância relativa é de $8,5 \%$ e requer mais cuidados. Os conceitos, dentro dos construtos, foram assumidos como uniformemente ponderados.

\section{Quadro 3: Julgamentos dos decisores.}

\begin{tabular}{|c|c|c|c|c|c|}
\hline & 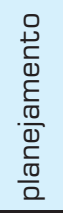 & 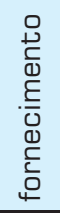 & 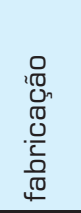 & 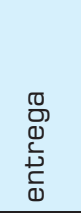 & 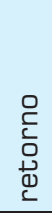 \\
\hline planejamento & 1 & 7 & 7 & 3 & 9 \\
\hline fornecimento & & 1 & $1 / 3$ & $1 / 7$ & 3 \\
\hline fabricação & & & 1 & $1 / 7$ & 3 \\
\hline entrega & & & & 1 & 9 \\
\hline retorno & & & & & 1 \\
\hline
\end{tabular}

$$
\begin{array}{r}
\text { Índice } \boldsymbol{S C}=0,505 .[\text { Planejamento }]+0,055 .[\text { Fornecimento }] \\
+0,085 .[\text { Fabricação }]+0,324 .[\text { Entrega }]+0,031 .[\text { Retorno }] \\
\text { Equação 1; }
\end{array}
$$

A seguir, foram feitos os trabalhos de campo, em três duplas, cada uma formada por um praticante do grupo de pesquisa e um gestor de cadeia, sob supervisão geral do líder de pesquisa. Cada dupla avaliou a cadeia do gestor, levantando, em diversas visitas e entrevistas em profundidade, com o apoio de outros gestores da empresa focal e de empresas participantes da $\mathrm{SC}$, a situação dos vinte e cinco conceitos $[$ muito ruim $=0 ;$ ruim $=5 ;$ médio $=10 ;$ bom $=15$; muito bom $=20]$.

O resultado surge na Tabela 2. Nas duas primeiras colunas enumeram-se os construtos e os conceitos. Nas colunas seguintes tem-se a avaliação primária do conceito, a avaliação ponderada, que multiplica a avaliação primária pelo peso do construto, e a avaliação parcial do construto, a soma das avaliações ponderadas. Na última linha têm-se as avaliações finais e a nota de desempenho das cadeias.

\section{Discussão}

A discussão ocorre em duas etapas: validação dos resultados e possibilidade de contribuição a uma futura teoria.

A primeira validação é quanto à questão de pesquisa: o desempenho das SCs é realmente diferente, ou as diferenças de resultados são variações naturais decorrentes do processo de

Figura 4: Grafo da SC exemplificada.

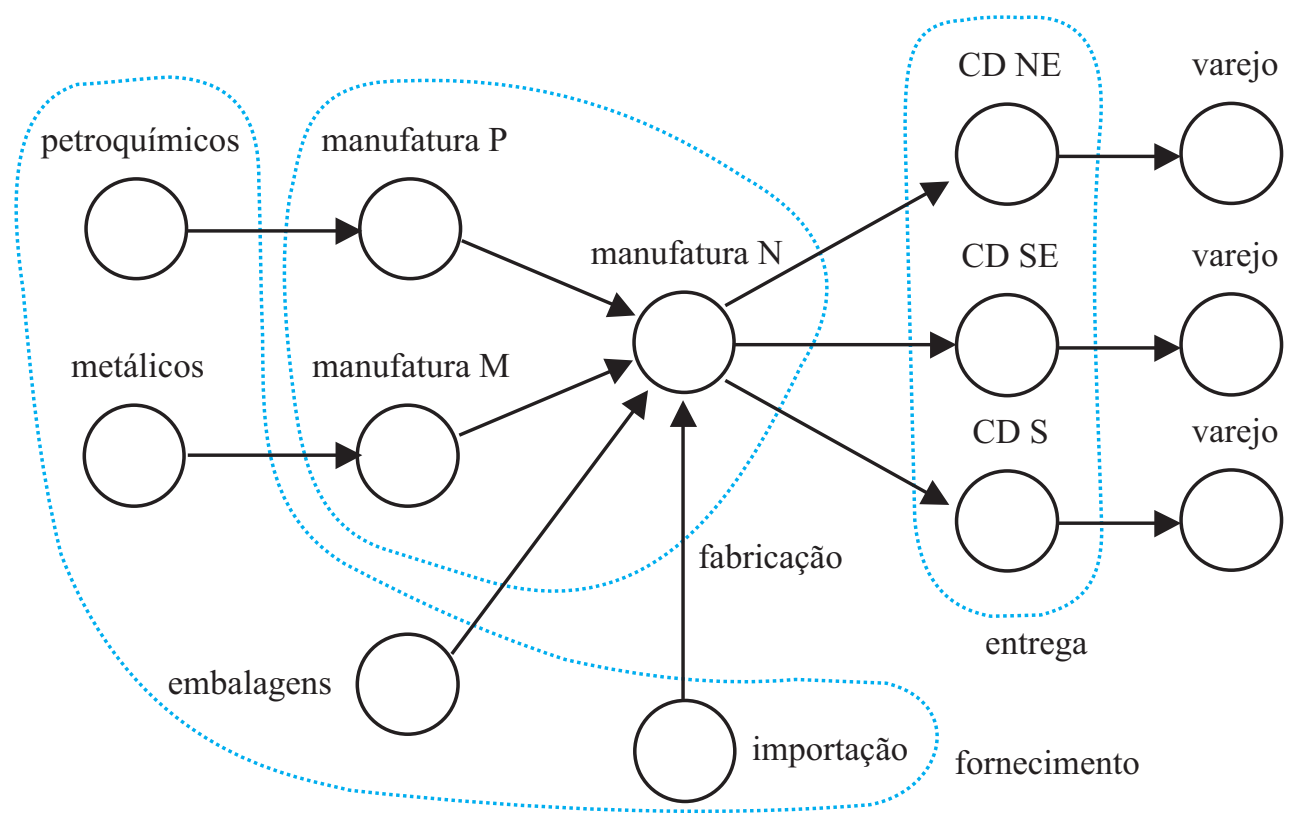


avaliação? As avaliações formam uma amostra emparelhada: um mesmo experimento foi aplicado a mais de um objeto, assumindo-se como fonte única de variação os desempenhos reais. O teste usado surge em Dowing e Clark (2003).

Admite-se que o valor absoluto das diferenças entre as $n=25$ avaliações de cada par de SCs provenham de uma distribuição normal com média $\mu_{d}$ e variância $\sigma_{\mathrm{d}}^{2}$. A hipótese nula é $H_{0}=\left[\mu_{d}=0\right]$. Se $x_{d i}$ é o valor absoluto da diferença entre duas avaliações do conceito $i$, a média $\left[X_{d}=\Sigma x_{d i}\right] / n$ seguirá uma distribuição normal cuja média é $\mu_{d}$ e a variância é $\sigma_{d}^{2} / n$. Se $H_{0}$ é verdadeira, a estatística de teste $T$, dada pela equação 2 , provém de uma distribuição $t$ com graus de

Tabela 2: Resultados da avaliação das três cadeias.

\begin{tabular}{|c|c|c|c|c|c|c|c|c|c|c|}
\hline \multirow{2}{*}{$\begin{array}{l}\text { CONSTRUTO } \\
\end{array}$} & \multirow[b]{2}{*}{ CONGEITO } & \multicolumn{3}{|c|}{ CADEIA A } & \multicolumn{3}{|c|}{ GADEIA B } & \multicolumn{3}{|c|}{ GADEIA C } \\
\hline & & PRIM. & POND. & PARCIAL & PRIM. & POND. & PARCIAL & PRIM. & POND. & PARCIAL \\
\hline \multirow{5}{*}{$\begin{array}{l}\text { Planejamento } \\
0,505\end{array}$} & 1 & 5 & 2,525 & 15,15 & 10 & 5,05 & 12,63 & 5 & 2,525 & 20,2 \\
\hline & 2 & 5 & 2,525 & & 5 & 2,525 & & 5 & 2,525 & \\
\hline & 3 & 5 & 2,525 & & 0 & 0 & & 5 & 2,525 & \\
\hline & 4 & 5 & 2,525 & & 5 & 2,525 & & 10 & 5,05 & \\
\hline & 5 & 10 & 5,05 & & 5 & 2,525 & & 15 & 7,575 & \\
\hline \multirow{5}{*}{$\begin{array}{l}\text { Fornecimento } \\
0,005\end{array}$} & 1 & 5 & 0,275 & 2,48 & 10 & 0,55 & 1,93 & 15 & 0,825 & 2,75 \\
\hline & 2 & 5 & 0,275 & & 5 & 0,275 & & 10 & 0,55 & \\
\hline & 3 & 10 & 0,55 & & 5 & 0,275 & & 10 & 0,55 & \\
\hline & 4 & 10 & 0,55 & & 5 & 0,275 & & 10 & 0,55 & \\
\hline & 5 & 15 & 0,825 & & 10 & 0,55 & & 5 & 0,275 & \\
\hline \multirow{5}{*}{$\begin{array}{l}\text { Produção } \\
0,085\end{array}$} & 1 & 5 & 0,425 & 4,25 & 20 & 1,7 & 5,53 & 15 & 1,275 & 5,53 \\
\hline & 2 & 10 & 0,85 & & 10 & 0,85 & & 15 & 1,275 & \\
\hline & 3 & 10 & 0,85 & & 10 & 0,85 & & 10 & 0,85 & \\
\hline & 4 & 15 & 1,275 & & 15 & 1,275 & & 10 & 0,85 & \\
\hline & 5 & 10 & 0,85 & & 10 & 0,85 & & 15 & 1,275 & \\
\hline \multirow{5}{*}{$\begin{array}{l}\text { Entrega } \\
0,324\end{array}$} & 1 & 5 & 1,62 & 14,58 & 10 & 3,24 & 11,34 & 5 & 1,62 & 14,58 \\
\hline & 2 & 10 & 3,24 & & 5 & 1,62 & & 10 & 3,24 & \\
\hline & 3 & 10 & 3,24 & & 5 & 1,62 & & 10 & 3,24 & \\
\hline & 4 & 10 & 3,24 & & 5 & 1,62 & & 10 & 3,24 & \\
\hline & 5 & 10 & 3,24 & & 10 & 3,24 & & 10 & 3,24 & \\
\hline \multirow{5}{*}{$\begin{array}{l}\text { Retorno } \\
0,031\end{array}$} & 1 & 10 & 0,31 & 1,86 & 15 & 0,465 & 1,4 & 15 & 0,465 & 1,71 \\
\hline & 2 & 10 & 0,31 & & 5 & 0,155 & & 15 & 0,465 & \\
\hline & 3 & 15 & 0,465 & & 10 & 0,31 & & 10 & 0,31 & \\
\hline & 4 & 10 & 0,31 & & 5 & 0,155 & & 10 & 0,31 & \\
\hline & 5 & 15 & 0,465 & & 10 & 0,31 & & 5 & 0,155 & \\
\hline \multicolumn{2}{|l|}{ Total } & & & 38,32\% & & & $32,81 \%$ & & & $44,77 \%$ \\
\hline
\end{tabular}

Tabela 3: Análise estatística comparada entre as avaliações das SCs.

\begin{tabular}{|c|c|c|c|c|c|}
\hline \multirow{2}{*}{ COMPARAÇÃO } & $\begin{array}{c}\text { MÉdIA DAS } \\
\text { DIFERENÇAS }\end{array}$ & $\begin{array}{c}\text { DESVIO- } \\
\text { PADRÄ̈O DAS } \\
\text { DIFERENÇAS }\end{array}$ & ESTATÍSTICA T & T CRÍTICO & Ho \\
\hline$[\mathrm{A}-\mathrm{B}]$ & 3,8 & 3,32 & 5,73 & 2,06 & rejeitada \\
\hline$[\mathrm{C}-\mathrm{B}]$ & 4,4 & 2,63 & 8,37 & 2,06 & rejeitada \\
\hline$[\mathrm{C}-\mathrm{A}]$ & 3,4 & 3,74 & 4,54 & 2,06 & rejeitada \\
\hline
\end{tabular}


liberdade $g l=24$. Na Tabela 3, apresentam-se as estatísticas $T$, o $T_{\text {crítico }}$ e a decisão sobre $H_{0}$. As três SC's têm desempenhos diferentes.

$$
T=\frac{\sqrt{n} \cdot\left(\bar{x}_{d}\right)}{s_{d}} \quad \text { Equação } 2
$$

A segunda validação diz respeito à confiabilidade das avaliações. Para tanto, usa-se o teste do alfa de Crombach (HAIR et al., 1998): um alfa maior do que 0,50 indica confiabilidade satisfatória em pesquisas exploratórias. Caso não se atinja este limite, deve-se excluir um item e recalcular o alfa. Os itens cuja exclusão mais aumentarem o alfa são os que mais contribuíram para a perda de confiabilidade. A conceituação destes itens deve ser mais bem esclarecida, já que podem ter suscitado dúvidas nos avaliadores.
Na Tabela 4 apresenta-se o teste. Os conceitos a reformular eventualmente são: a flexibilidade na fabricação, os custos em fornecimentos e a ética ambiental. Comparam-se as SCs na Tabela 5. A cadeia $\mathrm{C}$ possui os melhores desempenhos, a não ser em retorno de materiais.

Uma crítica que pode ser feita à análise precedente diz respeito a uma possível falta de mútua exclusividade entre critérios de desempenho, já mencionada. Para Hogarth (1988), é muito difícil uma abordagem científica encontrar construtos totalmente exclusivos capazes de descrever exaustivamente uma situação complexa. Saaty (1991) afirma que, na compreensão humana da natureza, pode haver alguma inconsistência, refletida em perda de exclusividade nos construtos, e que os juízos de decisores podem violar propriedades da racionalidade, tais como a transitividade. Portanto, algum sombreamento deve ser esperado em es-

Tabela 4: Confiabilidade das avaliações (usado software SPSS v.10).

\begin{tabular}{|c|c|c|c|}
\hline CONSTRUTO & CONCEITO & $\begin{array}{l}\text { ALFA DE CROMBACH SE O } \\
\text { ITEM FOR RETIRADO }\end{array}$ & $\begin{array}{c}\text { ALFA DE } \\
\text { CROMBACH }\end{array}$ \\
\hline Planejamento & $\begin{array}{l}\text { alinhamento estratégico } \\
\text { formulação das estratégias } \\
\text { desdobramento da estratégia } \\
\text { medição do desempenho } \\
\text { política da qualidade }\end{array}$ & $\begin{array}{l}0,62 \\
0,51 \\
0,41 \\
0,41 \\
0,28\end{array}$ & 0,51 \\
\hline Fornecimento & $\begin{array}{l}\text { flexibilidade de fornecimento } \\
\text { pontualidade no fornecimento } \\
\text { qualidade do fornecimento } \\
\text { condições de negociação } \\
\text { custos de fornecimento }\end{array}$ & $\begin{array}{l}0,46 \\
0,41 \\
0,41 \\
0,41 \\
0,65\end{array}$ & \\
\hline Fabricação & $\begin{array}{l}\text { flexibilidade da fabricação } \\
\text { pontualidade na fabricação } \\
\text { qualidade da fabricação } \\
\text { processo de fabricação } \\
\text { custos de fabricação } \\
\end{array}$ & $\begin{array}{l}0,71 \\
0,41 \\
0,51 \\
0,62 \\
0,41\end{array}$ & \\
\hline Entrega & $\begin{array}{l}\text { flexibilidade na entrega } \\
\text { pontualidade da entrega } \\
\text { qualidade da entrega } \\
\text { condições de negociação } \\
\text { custos de entrega }\end{array}$ & $\begin{array}{l}0,62 \\
0,41 \\
0,41 \\
0,41 \\
0,51\end{array}$ & \\
\hline Retorno & $\begin{array}{l}\text { reciclabilidade } \\
\text { devolução de itens } \\
\text { conformidade legal } \\
\text { custos de devolução } \\
\text { ética ambiental }\end{array}$ & $\begin{array}{l}0,54 \\
0,28 \\
0,54 \\
0,41 \\
0,65\end{array}$ & \\
\hline
\end{tabular}


truturas, cabendo ao pesquisador lidar para que não seja demasiado. $\mathrm{O}$ autor sugere medir a consistência dos julgamentos, procedendo a eventuais correções, o que foi feito na presente pesquisa.

Se a falta de exclusividade surgir sob a forma de dependência entre variáveis de planejamento e variáveis de campo, aquelas podem ser entendidas como precursoras destas e a sua contribuição ao desempenho considerada em nível intermediário, não final. Sintetizando, o método proposto mede um processo intermediário, o planejamento, necessário mas não suficiente, e o resultado de campo. O desempenho global combina processo e resultado.

Os resultados da pesquisa podem ser um passo intermediário em direção a uma teoria para a medição de desempenho em SC. Liga-se a metodologia ora proposta a um conceito explorado em Gasparetto (2003) e em Hansen (2004): a medição do desempenho de uma operação complexa deve refletir a complexa estratégia nela empregada, uma parte refletindo os objetivos e outra parte os meios para alcançá-los. Para o caso, admitiu-se o referencial teórico do SCOR para a escolha de objetivos e meios, representados pela estrutura do Quadro 2.

Também aproveita-se a contribuição de Pires e Aravecchia (2001), segundo a qual devem-se agregar indicadores específicos das unidades de negócios a indicadores gerais da cadeia. Conforme antevisto pelos autores, grandezas cumulativas, tal como o tempo até a entrega, o inventário e o custo da entrega, são compostas por parcelas que se somam ao longo da cadeia. Grandezas dependentes, tais como a qualidade intrínseca de materiais e a capabilidade de processos, devem ser correlacionadas. Cada participante terá indicadores internos, ligados às estratégias funcionais, tais como RH e finanças, e indicadores compartilhados, calculados individualmente e comunicados à gestão da SC.

Acrescenta-se que grandezas intangíveis, tais como condições de negociação ou ética ambiental, que são, por natureza, de difícil mensuração direta, exigem mensuração por variáveis proxi, que podem ser obtidas por julgamento de decisores.
Algumas questões teóricas adicionais podem ser endereçadas na discussão dos resultados de pesquisa. $\mathrm{Na}$ fase de fornecimento, talvez interesse medir apenas o maior tempo de atravessamento. Apenas este contribui para o atraso da fase, pois dominará os demais na montagem. Quanto aos inventários, todos devem ser medidos, pois todos contribuem para o inventário da fase. $\mathrm{Na}$ fase de distribuição, talvez interesse separar os CDs (tempos até a entrega diferentes para regiões diferentes). Em cadeias de múltiplos produtos, talvez interesse medir só o produto mais importante ou mais complexo, assumindo-se que, controlado este, também os demais estarão sob controle.

O Quadro 4 mostra uma proposta inicial de indicadores, construída sob a ótica metodológica proposta por esta pesquisa. Os indicadores foram escolhidos segundo a estrutura de idéias do Quadro 2, associando os conceitos que sustentam os construtos fornecimento, fabricação, distribuição e retorno a variáveis físicas que apreendam objetivamente o comportamento das fontes de desempenho ligadas a estes macroprocessos. Entende-se que o planejamento, sendo intangível e apriorístico, neste estágio da medição, não requeira mais indicadores objetivos. A importância relativa de cada indicador é calculada como anteriormente. Se um conceito é apreendido por mais de um indicador, uma alternativa inicial é distribuir importâncias uniformemente entre estes. Por serem grandezas aleatórias, cada indicador exige uma teoria ou modelo de medição e um procedimento operacional de coleta, processamento e armazenamento, associado ao sistema de informação da SC. No processo ora proposto, o que é replicável é o procedimento de estruturação de idéias, escolha e ponderação de indicadores, não necessariamente os indicadores escolhidos para um caso e as suas ponderações.

Definidos os indicadores, as importâncias e as categorizações [ótima $=1$, boa $=0,75$, média $=0,5$, ruim $=0,25$, péssima $=0]$, por soma de produtos (importância relativa do indicador vezes categoria da situação) chega-se a um valor global de desempenho entre 0 e $100 \%$.

Tabela 5: Ordenações parciais e global das cadeias.

\begin{tabular}{|c|c|c|c|}
\hline CONSTRUTO & GADEIA A & CADEIA B & CADEIA C \\
\hline planejamento & $2^{\mathrm{a}}$ & 3aㅡ & 1 a \\
\hline suprimento & $2^{\mathrm{a}}$ & 3aㅡ & 1a \\
\hline fabricação & 3aㅡ & 1 a & 1 a \\
\hline entrega & 1aㅡ & 3aㅡ & 1a \\
\hline retorno & 1 a & 3aㅡ & $2^{\mathrm{a}}$ \\
\hline global & 2 a & 3aㅡ & $1 \underline{a}$ \\
\hline
\end{tabular}


Quadro 4: Indicadores para SC.

\begin{tabular}{|c|c|c|}
\hline CONSTRUTO & CONGEITO & INDIGADORES \\
\hline \multirow{5}{*}{ fornecimento } & flexibilidade & -\% de fornecimentos satisfatórios extra-contratuais em valor e em unidades; \\
\hline & pontualidade & $\begin{array}{l}\text {-\% de fornecimentos em unidades (toneladas, peças, etc.) na data devida; } \\
\text {-\% de fornecimentos em \$ na data devida; } \\
\text {-tempo esperado (média e variabilidade) até a entrega de uma unidade fornecida; } \\
\text {-inventário médio em unidades e em \$ em fornecimento; }\end{array}$ \\
\hline & qualidade & $\begin{array}{l}\text {-\% de fornecimentos em unidades (toneladas, peças, etc.) aceitos na primeira vez; } \\
\text {-\% de fornecimentos em } \$ \text { aceitos na primeira vez; }\end{array}$ \\
\hline & negociação & - nível de satisfação dos fornecedores em relação à empresa focal (proxi); \\
\hline & custos & $\begin{array}{l}\text {-custo dos fornecimentos por unidade do produto principal; } \\
\text {-participação \% dos fornecimentos no custo do produto principal; }\end{array}$ \\
\hline \multirow{5}{*}{ fabricação } & flexibilidade & -\% de ordens de fabricação satisfatórias extra-contratuais em valor e em unidades; \\
\hline & velocidade & $\begin{array}{l}\text {-\% de ordens de fabricação em unidades (toneladas, peças, etc.) no prazo; } \\
\text {-\% de ordens de fabricação em } \$ \text { cumpridas no prazo; } \\
\text {-tempo esperado (média e variabilidade) até a fabricação de uma unidade; } \\
\text {-inventário médio em unidades e em } \$ \text { em processamento; }\end{array}$ \\
\hline & qualidade & $\begin{array}{l}\text {-\% de refugo e retrabalho em unidades (toneladas, peças, etc.); } \\
\text {-\% de refugo e retrabalho em } \$ \text {; }\end{array}$ \\
\hline & processo & $\begin{array}{l}\text {-disponibilidade do principal processo de fabricação (\% de tempo); } \\
\text {-capabilidade do principal processo de fabricação (CP, CPK); }\end{array}$ \\
\hline & custo & $\begin{array}{l}\text {-custo da fabricação por unidade do produto principal; } \\
\text {-participação \% da fabricação no custo do produto principal; }\end{array}$ \\
\hline \multirow{5}{*}{ entrega } & flexibilidade & -\% de entregas satisfatórias extra-contratuais em valor e em unidades; \\
\hline & pontualidade & $\begin{array}{l}\text {-\% de entregas em unidades (toneladas, peças, etc.) no prazo; } \\
\text {-\% de entregas em \$ cumpridas no prazo; } \\
\text {-tempo esperado (média e variabilidade) até a entrega de uma unidade; } \\
\text {-inventário médio em unidades e em \$ em trânsito; }\end{array}$ \\
\hline & qualidade & $\begin{array}{l}\text {-\% de entregas em unidades (toneladas, peças, etc.) sem avarias e integrais; } \\
\text {-\% de entregas em } \$ \text { sem avarias e integrais; }\end{array}$ \\
\hline & negociação & - nível de satisfação dos distribuidores em relação à empresa focal (proxi); \\
\hline & custos & $\begin{array}{l}\text {-custo da entrega por unidade do produto principal; } \\
\text {-participação \% da entrega no custo do produto principal; }\end{array}$ \\
\hline \multirow{5}{*}{ retorno } & reciclabilidade & $\begin{array}{l}\text {-\% de materiais reciclados na cadeia, em unidades; } \\
\text {-\% de materiais reciclados na cadeia, em } \$ \text {; }\end{array}$ \\
\hline & $\begin{array}{l}\text { devolução de } \\
\text { itens }\end{array}$ & $\begin{array}{l}\text {-\% de materiais devolvidos reaproveitados, em unidades; } \\
\text {-\% de materiais devolvidos reaproveitados, em } \$ \text {; } \\
\text {-inventário de devolvidos, em unidades e em } \$ \text {; }\end{array}$ \\
\hline & \begin{tabular}{|l|} 
conformidade \\
legal \\
\end{tabular} & -valor pago por autuações; \\
\hline & $\begin{array}{l}\text { custos de } \\
\text { devolução }\end{array}$ & $\begin{array}{l}\text {-custo da devolução por unidade do produto principal; } \\
\text {-participação \% da devolução no custo do produto principal; }\end{array}$ \\
\hline & ética ambiental & - nível de satisfação dos participantes da cadeia com suas ações ambientais (proxi). \\
\hline geral & geral da cadeia & $\begin{array}{l}\text {-valor esperado e variabilidade do tempo até a entrega; } \\
\text {-inventário total na cadeia em unidades e em \$; } \\
\text {-custo por unidade do produto principal; } \\
\text {-\% entregas com qualidade (prazo, avarias, quantidade); } \\
\text {-correlação entre os indicadores locais de qualidade. }\end{array}$ \\
\hline
\end{tabular}


$\mathrm{O}$ conjunto de indicadores atende aos cinco quesitos de Beamon (1996): tem (i) abrangência, pois inclui todos os aspectos da cadeia; (ii) universalidade, pois o valor global é comparável; (iii) mensurabilidade, pois os indicadores são facilmente mensuráveis; (iv) consistência, pois refletem uma estratégia, baseada no SCOR; e (v) conectividade, pois os participantes oferecem indicadores para a gestão da SC. O método também atende a Dornier et al. (2000), que apregoam que as medições devem acompanhar as mudanças no comportamento interno da $\mathrm{SC}$ e no cenário de competição, pois podem-se atualizar ponderações e conceitos. Os indicadores da cadeia apontam objetivos de clientes (custos, tempos e qualidade), uso dos recursos (inventário) e os indicadores dos construtos apontam como estes objetivos foram alcançados.

\section{s resultados da pesquisa podem ser um passo intermediário em direção a uma teoria para a medição de desempenho em SC.}

Finalmente, pode-se comparar os indicadores ora sugeridos com os mencionados na versão 8.0 do SCOR. Por exemplo, na página 10 do SCOR Overview 8.0 (SCC, 2006), surgem as seguintes métricas de primeiro nível: atendimento perfeito de ordens; tempo de ciclo para atendimento de ordens; flexibilidade da cadeia à jusante; adaptabilidade da cadeia à jusante; adaptabilidade da cadeia à montante; custo de gerenciamento da cadeia; custo dos bens vendidos; tempo de ciclo de valores financeiros; retorno de investimento em ativos fixos; e retorno de investimento em trabalho. O referencial relaciona estas métricas a fatores estratégicos: confiabilidade, responsividade, flexibilidade, custo e ativos. Estas métricas se originam de medições em níveis inferiores, geralmente associadas a elementos mais específicos de processo, abordados pelo modelo. Algumas semelhanças e diferenças entre os conjuntos de indicadores surgem, tais como a medição de variabilidade em algumas grandezas, ora proposta. Por demandar esforços adicionais e estar fora do objetivo de pesquisa, remete-se à continuidade uma comparação exaustiva entre os dois referenciais.

\section{CONSIDERAC̣ÕES FINAIS E CONTINUIDADE DE PESQUISA}

O objetivo deste trabalho foi propor uma metodologia para a construção de uma estrutura de mensurações, capaz de oferecer uma avaliação numérica compreensiva do desempenho de cadeias de suprimentos. A base conceitual da estrutura foi extraída do modelo SCOR de referência de gestão de SC. A mesma foi ponderada pelo AHP, chegando-se a uma distribuição de importância que reflete a situação atual da cadeia, segundo julgamento de decisores, e a uma função linear de relacionamento entre construtos latentes e o termo teórico do modelo, o desempenho da cadeia de suprimentos.

Para teste e refinamento do método, três cadeias, com similaridades, foram avaliadas, chegando-se a uma estrutura de preferências formada por números proporcionais aos desempenhos. Agestão das cadeias não segue o SCOR, o que, de certo modo, reforça a generalidade dos achados. Ao fim, extrapolaram-se os resultados, propondo-se, para outras pesquisas, um conjunto de indicadores de medição objetiva. Sucessivas medições gerarão séries históricas que podem ser o elo de realimentação da gestão da SC.

Caso se queira replicar o método ora proposto a outra SC, basta aplicá-lo e encontrar outros conceitos e ponderações, chegando a um instrumento específico de avaliação da nova SC. Vale reforçar a sugestão já mencionada de uma comparação exaustiva entre os indicadores obtidos com os sugeridos pelo SCOR 8.0.

Para fortalecimento dos achados de pesquisa, sugere-se o uso de método multicriterial alternativo ao AHP, haja vista que este permite alguma inconsistência na tradução das preferências dos decisores. Sugere-se a inclusão de hierarquias não-lineares e interdependência entre os fatores de decisão, o que exigirá outros métodos multicriteriais.

Por fim, sugerem-se outros tipos de SC, já mencionados, e ao menos uma aplicação completa do método: formulação e ponderação da estrutura de desempenho, definição de indicadores, medição e categorização da situação dos indicadores e cálculo de um valor numérico global para o desempenho da SC. 
BEAMON, B. Measuring Supply Chain Performance. International Journal of Operations \& Production Management, v. 19 , n. 3, p. 275-292, 1999.

BITITCI, U.; NUDURUPATI, S.; TURNER, T.; CREIGHTON, $\mathrm{S}$. Web enable performance measurements: management implications. International Journal of Operations and Production Management, v. 22, n. 11, p. $1273-1287,2002$.

BNQP: BALDRIDGE NATIONAL QUALITY PROGRAM, Criteria for performance excelence. Disponível em: < http://www. quality.nist.gov/Business_Criteria.htm $>$. Acesso em: março de 2006.

BORN, G. Process management to quality improvement. Chichester, UK: John Wiley \& Sons, 1994.

BOWERSOX, D.; CLOSS, D. Logística empresarial. São Paulo: Atlas, 2001.

CAMP, R. Benchmarking. São Paulo: Pioneira, 1994.

CHAN, F. Performance Measurement in a Supply Chain The International Journal of Advanced Manufacturing Technology, v 21, n. 7 , p. $534-548,2003$

CHAN, F.; QI, H. Feasibility of performance measurement system for supply chain: a process-based approach and measures. Integrated Manufacturing Systems, v. 14, n. 3, p. 179-190, 2003.

COOPER, M.; ELLRAM, L. Characteristics of supply chain management and the implications for purchasing and logistics strategy. The International Journal of Logistics Management, v. 4, n. 2, p. 13-24, 1993.

CRISTOPHER, M. Logística e gerenciamento da cadeia de suprimentos. S. Paulo: Pioneira Thomson Learning, 2002.

DAVENPORT, T. Reengenharia de processo. Rio Janeiro: Campus, 1994

DORNIER, P.; ERNST, R.; FENDER, M.; KOUVELIS, P. Logística e operações globais: texto e casos. São Paulo: Atlas, 2000.

DOWING, D.; CLARK, J. Estatística aplicada. São Paulo: Saraiva, 2003.
ENSSLIN, L.; MONTIBELLER, G ; NORONHA, S. Apoio à decisão. Florianópolis: Insular, 2001.

FRENCH, S. Decision Theory: an introduc tion to the mathematics of rationality. Chichester, UK: Ellis Horwood, 1986.

FPNQ: FUNDACÃO DO PRÊMIO NACIONAL DA QUALIDADE. Critérios de Excelência 2004. Disponível em: < http//www.fpnq. org.br>. Acesso em: março de 2006.

GASPARETTO, V. Proposta de uma sistemática para avaliação de desempenho em cadeias de suprimentos. Tese de doutorado. EPS - UFSC, Florianópolis, 2003.

GILMOUR, P. Benchmarking supply chain operations. International Journa of Physical Distribution \& Logistics Management, v. 29, n. 4, p. 259-266, 1999.

GOMES, L.; GOMES, C.; ALMEIDA, A Tomada de decisão gerencial: enfoque multicritério. São Paulo: Atlas, 2002.

GOMES, C.; YASIM, M.; LISBOA, J. An examination of manufacturing organizations's performance evaluation: organizations's performance evaluation: analysis, implications and a framework
for future research. International Journa for future research. International Journal v. 24 , n. 5 , p. $488-513,2004$

GUNASEKARAN, A.., PATEL, C., TIRTIROGLU, E. Performance measures and metrics in a supply chain environment. International Journal of Operations \& Production Management, v. 21, n. $1 / 2$ p. $71-87,2001$

GUNASEKARAN, A., PATEL, C. MCGAUGHEY, R. A framework for supMCGAUGHEY, R. A framework for sup-
ply chain performance measurement. International Journal of Production Economics, v. 87, n. 3, p. 333-347, 2004.

HAIR, J.; TATHAM, R.; ANDERSON, R.; BLACK, W. Multivariate data analysis. New Jersey: Prentice-Hall, 1998.

HANSEN, P. Um modelo de avaliação de desempenho competitivo de cadeias produtivas. Tese de doutorado. PPGEP-UFRGS, Porto Alegre, 2004

HOEK R. "Measuring the unmeasurable" - measuring and improving performance in the supply chain. Supply Chain
Management: An International Journal, v. 3, n. 4, p. 187-192, 1998.

HOGARTH, R. Judgement and choice. Essex, UK: John Wiley and Sons, 1988.

HOLMBERG, S. A systems perspective on supply chain measurements. International Journal of Physical Distribution \& Logistics Management, v. 30 , n. 10 , p. $847-868$, 2000.

HRONEC, S. Vital signs: using quality, time, and cost performance measurements to chart your company's future. USA: Arthur Andersen Co., 1993.

KLEIJNEN J.; SMITS M. Performance metrics in supply chain management. Journal of the Operational Research Society, v. 54, n. 5, p. 507-514, 2003.

LAI, K.; NGAI, E.; CHENG, T. Measures for evaluating supply chain performance in transport logistics. Transportation Research Part E: Logistics and Transportation Review, v. 38, n. 6, p. 439-456, 2002.

LAKATOS, E.; MARCONI, M.: Metodologia científica. S. Paulo: Atlas, 1991.

LAMBERT, D.; POHLEN, T. Supply Chain Metrics The International Journal of Logistics Management, v. 12, n. 1, p. 1-19, 2001.

MELNICK, S.; STEWARD, D.; SWINK. M. Metrics and performance measurements in operations management: dealing with the metrics maze. Journal of Operations Management, 22, p. 219-217, 2004.

PEREIRA, J. Análise de dados qualitativos. S. Paulo: Edusp, 1999

PIRES, S.; ARAVECHIA, C. Measuring supply-chain performance. Anais da XII annual conference of POMS, Orlando, 2001.

PIRES, S. Gestão da cadeia de suprimentos (supply-chain management): conceitos, estratégias, práticas e casos. São Paulo: Atlas, 2004.

PULAT, B. Process Improvements through benchmarking. The TQM Magazine, v. 6 , n. 2, p. 37-40, 1994
RIBEIRO, A. Benchmarking das cadeias de suprimento. Disponível em: < http://www. cel.coppead.ufrj.br/fs-busca.htm?fraline.htm > . Acesso em: dezembro de 2003.

ROESCH, S. Projetos de estágio e de pesquisa em administração: guia para estágios, trabalhos de conclusão, dissertações e estudos de caso. São Paulo: Atlas, 1999.

SAATY, T.Multicriteria Decision Making: the Analytic Hierarchy Process. Pittsburgh: RWS Publications, 1991.

SALOMON, V;; MONTEVECCHI, J. Método de análise em redes: sucessor do método de análise hierárquica? Produto Produção. Porto Alegre, v. 2, n. 3 , p. 107-117, 1998.

SIMCH-LEVI, D.; KAMINSKY, P.; SIMCHEVI, E. Cadeia de suprimentos: projeto gestão. Porto Alegre: Bookman, 2003.

SSC. Supply-Chain Operations Reference Model (SCOR). Version 6.0. 2003, disponível em: <www.supply-chain.org> Acesso em: agosto de 2003.

SSC. Supply-Chain Operations Reference Model (SCOR). Version 8.0. 2003. Disponível em: <www.supply-chain. org > . Acesso em: novembro de 2006.

SLACK, N. et. al. Administração da produção. São Paulo: Atlas, 1997.

SHINGO PRIZE. Application Guidelines 2004-2005. disponível em: <http:// www.shingoprize.org/BusPrize/ BusinessGuidelines.pdf $>$. Acesso em: março de 2006

VOSS, C. Alternative paradigms for manufacturing strategy. International Journal of Operations and Production Management, v. 15 , n. 4 , p. 5-16, 1995.

YIN, R. Estudo de caso: planejamento e método. Porto Alegre: Bookman, 2001.

W. EDWARD DEMING INSTITUTE, Deming Prize Information. disponível em: < http:// www.deming.org/demingprize/prizeinfo. html > . Acesso em: março de 2006 


\section{- Reconhecimentos}

Deseja-se reconhecer a importância dada pela UAP\&PG da UNISINOS aos esforços de pesquisa do PPGEPS-UNISINOS. Também deseja-se salientar a importância do portal de periódicos da CAPES, que ofereceu uma parte das fontes de pesquisa e os relevantes comentários dos referees anônimos.

\section{- Sobre os autores}

\section{Miguel Afonso Sellitto}

Universidade do Vale do Rio dos Sinos - Unisinos

Professor e pesquisador do Programa de Pós-Graduação em Engenharia de Produção e Sistemas

End.: Av. Unisinos 950 - 93022-000 - São Leopoldo - RS

Tel.: (51) 3591-1122

E-mail: sellitto@unisinos.br

\section{Lia Weber Mendes}

Universidade do Vale do Rio dos Sinos - Unisinos

Coordenadora e professora dos cursos: Tecnólogo em Logística; Administração de Empresas, carreira em Logística; e MBA UNISINOS Gestão da Produção e Logística

End.: Av. Unisinos 950 - 93022-000 - São Leopoldo - RS

Tel.: (51) 3591-1122

E-mail: LWeber@unisinos.br 